\title{
Ipsilateral and concurrent breast cancer and atypical ductal hyperplasia: \\ Does atypia also need surgical excision?
}

\author{
By
}

\author{
Amanda L. Amin \\ MD, Southern Illinois University, 2007 \\ BS, Loyola University Chicago, 2003 \\ Submitted to the graduate degree program in Clinical Research and the Graduate Faculty of the \\ University of Kansas in partial fulfillment of the requirements \\ for the degree of Master of Science.
}

Chair: Sue Min Lai, MS, MBA, Ph.D.

Jamie L. Wagner, DO

Onalisa D. Winblad, MD

Fang Fan, MD, Ph.D.

Date Defended: 17 April 2019 
The thesis committee for Amanda L. Amin certifies that this is the approved version of the following thesis:

Ipsilateral and concurrent breast cancer and atypical ductal hyperplasia: Does atypia also need surgical excision?

Chair: Sue Min Lai, MS, MBA, Ph.D.

Date Approved: 1 May 2019 


\begin{abstract}
Background: Standard of care for management of ADH identified on percutaneous biopsy is surgical excision. Research efforts have focused on utilizing strict multidisciplinary review to identify patients at lowest risk for upgrade that may benefit from omission of surgery. However, having an ipsilateral breast cancer, in addition to the site of $\mathrm{ADH}$, has been an exclusion criterion for consideration of observation over excision of the site of ADH.

Methods: This retrospective analysis examined patients who had both a breast cancer and an additional site of ADH in the same breast diagnosed on percutaneous biopsy, who underwent surgical excision of both areas at our institution from 2008-2018. Imaging characteristics (size of cancer, size of $\mathrm{ADH}$, distance between cancer and $\mathrm{ADH}$, percutaneous biopsy technique) and pathologic features (histologic subtype of cancer, cancer grade and prognostic markers, extent of $\mathrm{ADH}$, presence of necrosis or micropapillary features in the $\mathrm{ADH}$ ) were reviewed from the biopsy, as well as the final surgical pathology at the site of ADH excision to determine features associated with ADH upgrade.

Results: Sixty-two women had biopsy proven $\mathrm{ADH}$ and a breast cancer at separate sites in the same breast over the 10-year study period. The overall upgrade rate at the site of ADH was $17.7 \%(\mathrm{n}=11)$, with 9 cases to ductal carcinoma in situ (DCIS) and 2 to invasive breast cancer (IBC). The most common associations with upgrade were the presence of ipsilateral DCIS over IBC $(\mathrm{p}=0.034)$, using ultrasound guidance for biopsy of ADH $(\mathrm{p}=0.019)$, and the presence of cell necrosis in the ADH $(\mathrm{p}=0.039)$. Neither the radiographic size of the ADH nor the distance of the $\mathrm{ADH}$ from the ipsilateral cancer were associated with upgrade. The group at lowest risk for upgrade had stereotactic biopsy of the site of $\mathrm{ADH}$ and no necrosis associated with $\mathrm{ADH}$, which resulted in $0 \%$ upgrade rate.
\end{abstract}


Conclusion: When an ipsilateral breast cancer is present, the upgrade rate at the site of ADH is on par with reported contemporary ADH upgrade rates without ipsilateral breast cancer present. Similar to those studies of ADH alone, upgrade was significantly associated with biopsy modality and presence of $\mathrm{ADH}$ necrosis. When considering the ipsilateral breast cancer, upgrade rate for $\mathrm{ADH}$ was not affected by the size of the cancer, size of atypia, or distance between the ipsilateral malignancy and atypia. This suggests that omission of surgical excision for ADH in patients with concurrent breast cancer may be appropriate, like those with isolated ADH, when a select low risk subset undergoing rigorous multidisciplinary review can be identified. 


\section{Acknowledgements}

I would like to thank my advisor Dr. Lai for her assistance on this project and my thesis committee chairwomen, Drs. Wagner, Winblad, and Fan, for their support of this project as content experts. I would particularly like to recognize Dr. Fan, who personally reviewed the biopsy pathology slides to confirm the diagnosis of $\mathrm{ADH}$ and to document $\mathrm{ADH}$ characteristics, which were not routinely reported in the pathology report. Without her assistance, this project and its conclusions would not be possible. 


\section{Table of Contents}

\section{Contents}

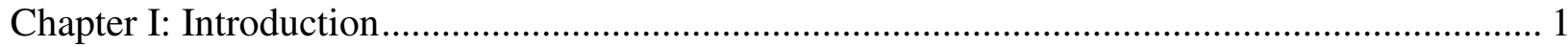

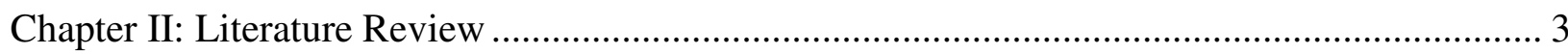

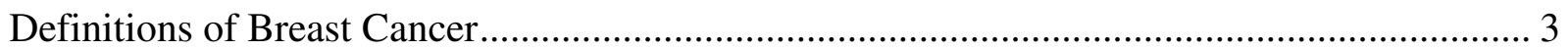

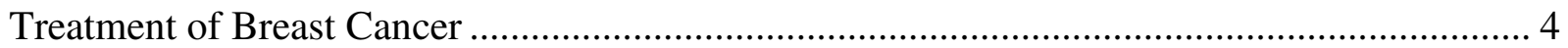

Definitions of Atypical Ductal Hyperplasia ........................................................................ 5

Treatment of Atypical Ductal Hyperplasia .............................................................................. 6

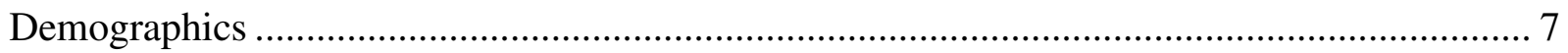

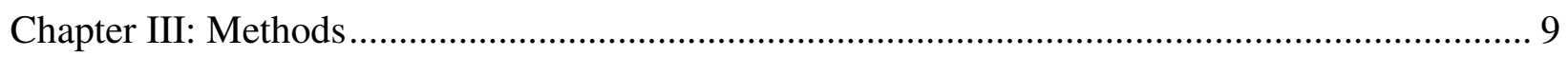

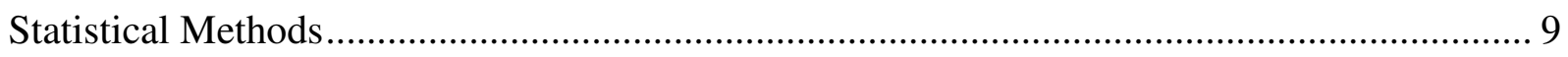

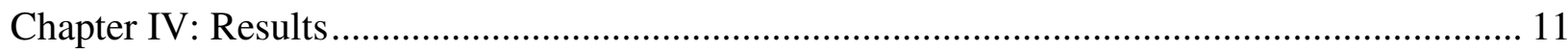

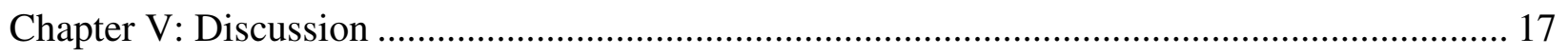

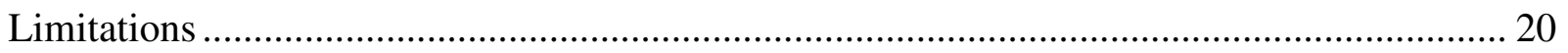

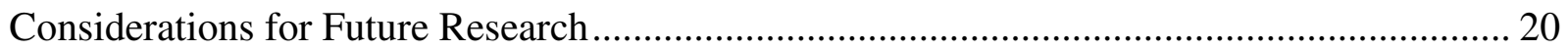

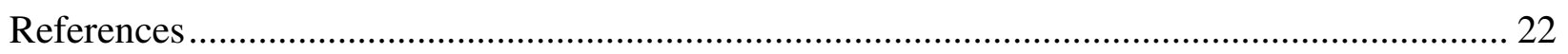




\section{List of Figures}

Figure 1: Surgical pathology at site of ADH.

\section{List of Tables}

Table 1: Patient characteristics .......................................................................................... 12

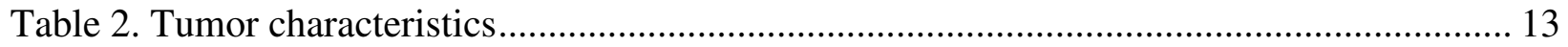

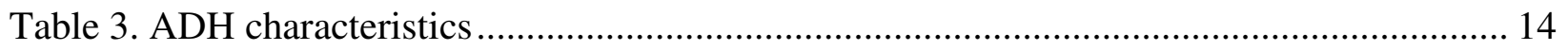

Table 4. Bivariate analysis of variables associated with upgrade ........................................... 16

Table 5. Multivariate analysis of variables associated with upgrade..................................... 16 


\section{Chapter I: Introduction}

Breast cancer is the second most common cancer among women in the United States, with more than 252,710 cases of invasive breast cancer (IBC) and 63,410 cases of ductal carcinoma in situ (DCIS) diagnosed in $2017 .{ }^{1}$ This translates into nearly 1 in 8 women in the United States being diagnosed with a breast cancer over the course of her lifetime. ${ }^{1}$ Standard of care for the surgical management of breast cancer is either mastectomy or lumpectomy followed by whole breast radiation, also known as breast conserving therapy (BCT). ${ }^{2,3}$

As imaging techniques and technology have improved, additional imaging abnormalities are being identified more frequently during the work up for an ipsilateral breast cancer. Standard of care for the management of an abnormal breast imaging finding, with an ipsilateral breast cancer, is percutaneous image-guided core needle biopsy, or surgical excision. ${ }^{4}$ More than 1 million percutaneous breast biopsies are performed for women with an abnormal imaging finding, $10-15 \%$ of which yield a finding of atypical hyperplasia. ${ }^{5}$

When women have undergone surgical excision for atypical ductal hyperplasia (ADH) identified on percutaneous biopsy, the upgrade rate to underlying malignancy has ranged wildly in the literature from $7-87 \% .^{6-8}$ Therefore, the National Comprehensive Cancer Network $(\mathrm{NCCN})$ guidelines recommends surgical excision for patients with ADH diagnosed on percutaneous biopsy due to this risk of upgrade to DCIS or IBC. ${ }^{9}$ However, as imaging and biopsy techniques continue to improve, the need for routine excision of all ADH has been called into question.

Multiple studies, including two studies performed at this institution, using more contemporary imaging and biopsy techniques, with strong multidisciplinary review, have identified lower upgrade rates, and attempted to identify patients at lowest risk for upgrade to 
DCIS or IBC who may avoid surgical excision. ${ }^{6,8,10-18}$ Attention has been focused on a combination of specific pathologic and radiographic features of ADH. Based on our data, patients with pathologic findings of $\mathrm{ADH}$ on percutaneous biopsy who have undergone extensive multidisciplinary review and meet criteria for low upgrade risk are offered observation and chemoprevention over surgical excision. ${ }^{16,18}$

One exclusion criteria in prior trials for consideration of observation of ADH over excision has been the presence of an ipsilateral DCIS or IBC. Historically, excision of both the ipsilateral breast cancer and the site of $\mathrm{ADH}$ has been performed, either with one large lumpectomy, two separate lumpectomies, or mastectomy. This accomplishes the goal of removing the known cancer and ruling out additional malignancy at the site of the ADH. The concern has always been that the woman may be at increased risk of underlying malignancy at the site of atypia if there is an ipsilateral malignancy. However, for many women desiring breast conservation, excising the area of $\mathrm{ADH}$ in addition to the ipsilateral cancer may result in significantly more breast tissue being removed, leading to a more profound cosmetic defect and breast asymmetry, or the inability to perform BCT at all, necessitating mastectomy.

The purpose of this study is to identify our institution's upgrade rate of ADH to DCIS or IBC when there is concurrent ipsilateral but separate site of DCIS or IBC. This upgrade rate has not been defined in the literature. If this rate of upgrade is significantly elevated there is justification for additional excision. However, if this rate of upgrade is low, or if a low risk for upgrade subset can be identified, then omission of surgical excision of the site of ADH may potentially be offered. This would allow women to have a more cosmetically appealing surgical option, while not compromising their oncologic outcome. 


\section{Chapter II: Literature Review}

\section{Definitions of Breast Cancer}

Breast cancer is the most common cancer diagnosis among women in the United States, with more than 252,710 cases of invasive breast cancer (IBC) and 63,410 cases of ductal carcinoma in situ (DCIS) diagnosed in 2017, and the second most common cause of cancer death. ${ }^{1}$ This translates into nearly 1 in 8 women in the United States being diagnosed with a breast cancer over the course of her lifetime. The normal structure of the breast is composed of lobules and ducts. To form a breast cancer, the tumor progresses from a benign proliferative state to in situ then invasive cancer through a series of genetic alterations and protein expression patterns. ${ }^{19}$

DCIS is carcinogenic cells that are contained within the duct and have not spread through the basement membrane into the surrounding fatty tissue of the breast. Because DCIS is still contained within the normal structure of the breast, more than $90 \%$ of these lesions are identified on screening imaging. More rare presentations of DCIS include palpable masses, nipple discharge, or nipple skin changes. ${ }^{20}$ IBC is a heterogenous group of epithelial breast malignancies, defined as the ability of the carcinogenic cells to invade adjacent normal tissue (such as the duct or the lobule), and can metastasize to sites distant to the breast. In general, IBC can be subclassified into invasive ductal carcinoma (IDC) and invasive lobular carcinoma (ILC), based on the loss of e-cadherin expression. IDC is the more common histologic subtype, accounting for approximately $80 \%$ of all IBC. ${ }^{21}$ DCIS is associated with an IBC in approximately $80 \%$ of cases of IDC, either within or around the invasive cancer. ${ }^{22}$ 
To further describe either the DCIS or IBC, the Nottingham grading system is applied to reflect the degree of differentiation of the carcinoma. Grading incorporates assessment of tubule formation, degree of nuclear atypia, and mitotic activity and is assigned on a scale of I-III. ${ }^{23}$ Prognostic markers are also obtained, which can help to define the clinical behavior of the tumor and guide systemic therapy recommendations. Commonly obtained markers include estrogen receptor (ER), progesterone receptor (PR), human epidermal growth factor receptor 2 gene or ERBB2 (HER2), and Ki-67. 70-80\% of IBC are positive for ER and/or PR and 15-30\% are HER2 amplified. HER2 is only routinely obtained for IBC, not DCIS. Ki-67 is a proliferation index, which, like histologic grade, can represent the growth rate or aggressive nature of the cancer.

\section{Treatment of Breast Cancer}

Management of breast cancer requires a multidisciplinary approach that incorporates local and systemic therapy for optimal outcomes. For the surgical management of breast cancer, before the 1970 's, all patients were treated with a radical mastectomy, which included removal of the breast, regional lymph nodes, underlying muscle, and overlying skin. NSABP B-04 relaxed this procedure into the now termed "modified radical mastectomy" where the skin and muscle are spared. Following this, several randomized clinical trials, which started accrual in the 1970's established that the extent of local therapy did not affect patient survival, the most important of which was NSABP B-06. ${ }^{2}$ B-06 was a comparison of lumpectomy with or without breast irradiation to total mastectomy. Patients with early stage breast cancer were randomized to one of these three arms from 1976-1984. At 20 years follow up, there continues to be no significant difference in overall survival, disease-free survival, or distant disease-free survival between the three groups. However, for the lumpectomy groups, those who received whole 
breast radiation had improved local control. This landmark trial supports standard of care for the management of breast cancer to be either complete removal of the breast (mastectomy) or removal of the tumor and preservation of the remaining breast tissue (lumpectomy) followed by whole breast radiation, also defined as breast conserving therapy (BCT).

\section{Definitions of Atypical Ductal Hyperplasia}

$\mathrm{ADH}$ is an epithelial proliferative lesion that forms in the terminal duct lobular unit that is found on $8-17 \%$ of core needle biopsies. ${ }^{24}$ Similar to DCIS, ADH demonstrates both cytologic atypia and architectural changes; but the atypia are quantitatively and qualitatively insufficient for a diagnosis of DCIS. Therefore, to differentiate DCIS from ADH, the size criteria of atypia involving only 1 or 2 ducts and measures less than $2 \mathrm{~mm}$ may be used to diagnose ADH. ${ }^{24,25}$ Because of this, sampling error with core needle biopsy demonstrating $\mathrm{ADH}$ can occur, resulting in an upgrade to DCIS or IBC on surgical excision when the full lesion is evaluated. In addition, the interobserver concordance for $\mathrm{ADH}$ is notoriously poor. ${ }^{26}$ The risk of upgrade has ranged widely in the literature from 7-87\%. Advancements have been made in biopsy techniques and more sophisticated imaging modalities such as magnetic resonance imaging (MRI) and tomosynthesis are being used to target breast abnormalities. Refining diagnostic criteria of ADH and subspecialization of pathologists have improved interobserver concordance rate. In addition, more contemporary studies have focused on multidisciplinary concordance between the radiographic and pathologic findings. These more contemporary studies have identified an upgrade rate, or finding DCIS or IBC at the time of surgical excision, to be $18-39 \% .^{8,11,12,27-30}$ $\mathrm{ADH}$ is also a non-obligate precursor to breast cancer and represents a global increased risk of future breast cancer in either breast. 


\section{Treatment of Atypical Ductal Hyperplasia}

When $\mathrm{ADH}$ is diagnosed on percutaneous core needle biopsy, surgical excision has been considered standard of care to rule out underlying malignancy. ${ }^{9}$ However, given that most ADH cases diagnosed by percutaneous biopsy are not upgraded to DCIS or IBC, routine surgical excision is concerning for overtreatment for the majority of women. Multiple studies have attempted to define a favorable subgroup with $\mathrm{ADH}$ on core needle biopsy who would not benefit from surgical excision, or be at lowest risk for upgrade. Some studies identified patient demographic information such as age at diagnosis or personal or family history of breast cancer as risk for upgrade. ${ }^{11,12,15,31,32}$ Other studies used radiographic features such as size of the target lesion, the percent of the target that was removed by the biopsy, or number of cores removed. ${ }^{13,15,29,33}$ Even other studies used pathologic features such as the number of foci of $\mathrm{ADH}$, or the presence of individual cell necrosis or micropapillary features. ${ }^{6,8,10,13,17}$

With these findings, multivariate models have been proposed, the two most common from MD Anderson Cancer Center (MDACC) and Mayo Clinic. In 2011, Nguyen and colleagues identified 140 patients with $\mathrm{ADH}$ and found the lowest risk of upgrade occurred in patients with $>95 \%$ removal of the target lesion, the target lesion not being associated with a mass, no cytologic atypia, and no individual cell necrosis. They found that patients meeting these criteria, regardless of the extent of involvement, had minimal risk of upgrade to DCIS or IBC of $<3 \%$ compared to the overall upgrade rate of $13.2 \% .{ }^{13}$ Pena and colleagues at Mayo then published their findings in a series of 399 patients, with an overall upgrade rate of $16 \%$. They found the lowest upgrade rate of $<5 \%$ in patients with no individual cell necrosis and either 1 focus of $\mathrm{ADH}$ with $>50 \%$ removal of the target or $>1$ focus of $\mathrm{ADH}$ with $\geq 90 \%$ removal of the target lesion. $^{34}$ 
The long-term safety of omission of surgical excision for ADH has also been described by MDACC, in the low-risk subgroup defined by Nguyen. In a study by Menen and colleagues, the risk of subsequent cancer was not elevated in the group that underwent observation compared to the group that required surgical excision. This suggests that omission of surgical excision in a select group of patients with the diagnosis of $\mathrm{ADH}$, meeting strict radiologic and histologic criteria, may be an oncologically safe option. ${ }^{35}$

This has led to investigation of our own institutional upgrade rate in attempt to identify features that define our lowest risk group. Retrospective review of 124 percutaneous biopsies with ADH from 2006-2015 identified an overall upgrade rate of $17.7 \% .{ }^{16}$ The patients at lowest risk for upgrade were those with the target lesion $<1 \mathrm{~cm}$ in size, $>50 \%$ of the target lesion removed by the biopsy, $<3$ foci of $\mathrm{ADH}$, and no individual cell necrosis. Though this was a small number in our studies, none of these patients upgraded to DCIS or IBC at the time of surgical excision. ${ }^{18}$ Based on our findings, women who meet these criteria after undergoing rigorous multidisciplinary review are offered observation and counseling with chemoprevention in our high-risk breast cancer prevention clinic over surgical excision.

However, if a woman has an ipsilateral breast cancer and breast imaging identifies an additional abnormality in that same breast, and BCT is desired, percutaneous biopsy is recommended to diagnose that additional abnormality. If ADH is identified on core needle biopsy, surgical excision is routinely recommended of that area, in addition to the area of cancer. Women with an ipsilateral breast cancer and a separate site of ADH have been excluded from prior studies evaluating the need for surgical excision v. observation at the site of ADH.

\section{Demographics}


Over the 10-year study period, 62 women were identified with both an ipsilateral breast cancer and a diagnosis of ADH on percutaneous biopsy at a site remote to the known malignancy, $37(59.7 \%)$ in the left breast and 26 (41.9\%) in the right breast. The majority of women were Caucasian (74.2\%) with a mean age of 59.2 years (std 11.08, range 30-86). Twentyseven $(43.5 \%)$ had a family history of breast cancer in a first or second degree relative and 3 (4.8\%) had a personal history of breast cancer (Table 1). 


\section{Chapter III: Methods}

A single institution retrospective review was performed from January 2008-August 2018. All women, age 18-90, diagnosed with ADH on percutaneous biopsy, with a separate site of ipsilateral DCIS or IBC, who underwent surgical excision of both sites were identified. Patients were excluded if they were male, had other types of atypia including atypical lobular hyperplasia or lobular carcinoma in situ, did not have the site of ADH excised, or if the ADH was associated with the malignancy and not at a separate site in the same breast. All breast imaging was reviewed for biopsy modality, size of the target lesion (both cancer and ADH), and distance of ADH from ipsilateral malignancy. All pathology reports from the percutaneous biopsy and from the time of definitive surgery were reviewed to assess the histologic tumor subtype, grade, prognostic markers, and presence of DCIS associated with the invasive component, as well as the presence of DCIS or IBC at the biopsy site of ADH on final pathology to define upgrade rate to underlying malignancy at the time of surgery. In addition, ADH-specific features on biopsy pathology were captured including number of atypical foci, presence of individual cell necrosis, and micropapillary features. Additional clinical features were noted including age at diagnosis, personal and family history of breast cancer, and ethnicity.

\section{Statistical Methods}

Categorical variables were summarized using frequencies. Chi-square and Fisher's exact test was performed when appropriate to test for associations between categorical demographic, clinical, radiologic, pathologic characteristics of patients, and upgrade rate at the site of ADH. Student's $t$ test was performed as univariate analysis for continuous variables. Multivariable logistic regression analysis was performed to identify variables that were significantly associated 
with upgrade to underlying malignancy. All analyses were performed with SAS software version 9.4 (SAS Institute Inc. Cary, NC) and a p-value of 0.05 was used to determine statistical significance. Data were collected in a Research Electronic Data Capture (REDCap) project. 


\section{Chapter IV: Results}

Invasive ductal carcinoma was the most common histologic subtype of ipsilateral malignancy $(n=40,64.5 \%)$ followed by DCIS $(n=18,29 \%)$ and invasive lobular carcinoma $(n=5$, 8.1\%). Most cancers were strongly hormone receptor $(\mathrm{ER} / \mathrm{PR})$ positive $(\mathrm{n}=54,87.1 \%)$ and very few IBC were HER2 amplified ( $\mathrm{n}=3,7 \%)$. The surgical procedure for management of the sites of cancer and ADH was most commonly mastectomy $(n=35,56.5 \%)$, followed by two separate lumpectomies $(\mathrm{n}=16,25.8 \%)$, and one large lumpectomy $(\mathrm{n}=11,17.7 \%$, Table 1$)$.

The average size of the IBC or DCIS was $2.03 \mathrm{~cm}$ (std 1.79, median 1.50, range 0.3-9.0 $\mathrm{cm}$ ) and the average distance between the site of malignancy and the site of ADH was $4.55 \mathrm{~cm}$ (std 2.44, median 4.0 range 1.0-12.0 cm, Table 2). The biopsy modality for diagnosis of ADH was evenly distributed between stereotactic $(n=21,33.9 \%)$, sonographic $(n=21,33.9 \%)$, and magnetic resonance $(n=20,32.3 \%)$ guidance (Table 2). Most had only 1-2 foci of ADH ( $n=44$, $71 \%)$, and a minority had micropapillary features $(n=4,6.7 \%)$ or individual cell necrosis $(n=5$, $8.3 \%$, Table 3).

Eleven women were found to have an underlying malignancy at the site of ADH on final surgical pathology, for an overall upgrade rate of $17.7 \%$ (95\% CI 8.2-27.3\%): 9 to DCIS and 2 to IBC. The remaining 51 women either had residual atypia or benign findings (Figure 1). There were no demographic details that were significantly associated with upgrade, but there was a non-significant trend toward younger patients and those of non-Caucasian ethnicity having a higher risk of upgrade (Table 4). The ipsilateral malignancy, histologic tumor type and tumor size were not statistically significantly associated with upgrade, however, when comparing invasive (IDC and ILC) to non-invasive (DCIS) cancer, DCIS was significantly associated with upgrade ( $\mathrm{p}=0.034$, Table 4). The presence of DCIS associated with IBC, tumor grade, and 
prognostic markers were all not significant. When focusing on the ADH characteristics, neither the size of the $\mathrm{ADH}$ on imaging nor the distance between the $\mathrm{ADH}$ and the cancer were significant for upgrade. The biopsy modality for diagnosis of ADH was significantly associated with upgrade, with ultrasound guidance being much more likely to upgrade to malignancy $(\mathrm{p}=0.019$, Table 2$)$. ADH associated with necrosis was significantly associated with higher upgrade rate to underlying malignancy $(\mathrm{p}=0.039)$, but the presence of micropapillary features or the number of foci (extent) of ADH was not (Table 3).

Table 1. Patient characteristics

\begin{tabular}{|c|c|c|c|c|}
\hline & $\begin{array}{l}\text { All patients with } \\
\text { ADH and ipsilateral } \\
\text { malignancy }\end{array}$ & Upgrade group & $\begin{array}{l}\text { No upgrade } \\
\text { group }\end{array}$ & $\mathrm{P}$ value \\
\hline No. of patients $(\%)$ & $62(100)$ & $11(17.7)$ & $51(82.3)$ & \\
\hline $\begin{array}{l}\text { Age at diagnosis, years [mean } \\
\text { (std)] }\end{array}$ & $59.2(11.08)$ & $57.3(12.53)$ & $59.7(10.84)$ & 0.215 \\
\hline $\begin{array}{l}\text { Family history of breast cancer } \\
\text { Yes } \\
\text { No }\end{array}$ & $\begin{array}{l}27(43.5) \\
35(56.5)\end{array}$ & $\begin{array}{l}4(36.4) \\
7(63.6)\end{array}$ & $\begin{array}{l}23(45.1) \\
28(54.9)\end{array}$ & 0.742 \\
\hline $\begin{array}{l}\text { Personal history of breast cancer } \\
\text { Yes } \\
\text { No }\end{array}$ & $\begin{array}{c}3(4.8) \\
59(95.2) \\
\end{array}$ & $\begin{array}{c}0 \\
11(100) \\
\end{array}$ & $\begin{array}{c}3(4.9) \\
48(94.1) \\
\end{array}$ & 1.000 \\
\hline $\begin{array}{l}\text { Ethnicity } \\
\text { Caucasian } \\
\text { African American } \\
\text { Hispanic } \\
\text { Asian/Middle eastern } \\
\end{array}$ & $\begin{array}{l}46(74.2) \\
9(14.5) \\
2(3.2) \\
5(8.1) \\
\end{array}$ & $\begin{array}{c}6(54.5) \\
3(27.3) \\
1(9.1) \\
1(9.1) \\
\end{array}$ & $\begin{array}{c}40(78.4) \\
6(11.8) \\
1(2.0) \\
4(7.8) \\
\end{array}$ & 0.166 \\
\hline $\begin{array}{l}\text { Surgery type } \\
\text { Mastectomy } \\
\text { Lumpectomy x } 1 \\
\text { Lumpectomy x } 2\end{array}$ & $\begin{array}{l}35(56.5) \\
11(17.7) \\
16(25.8)\end{array}$ & $\begin{array}{c}7(63.6) \\
3(27.3) \\
1(9.1)\end{array}$ & $\begin{array}{l}28(54.9) \\
8(15.7) \\
15(29.4) \\
\end{array}$ & 0.381 \\
\hline
\end{tabular}


Table 2. Tumor characteristics

\begin{tabular}{|c|c|c|c|c|}
\hline & $\begin{array}{c}\text { All patients with } \\
\text { ADH and ipsilateral } \\
\text { malignancy }\end{array}$ & $\begin{array}{l}\text { Upgrade } \\
\text { group }\end{array}$ & $\begin{array}{l}\text { No upgrade } \\
\text { group }\end{array}$ & $\mathrm{p}$-value \\
\hline $\begin{array}{l}\text { Clinical tumor size, cm [mean } \\
(\mathrm{std})]^{*}\end{array}$ & $2.03(1.79)$ & $2.56(2.57)$ & $1.92(1.61)$ & 0.115 \\
\hline $\begin{array}{l}\text { Histologic tumor type } \\
\text { IDC/ILC } \\
\text { DCIS }\end{array}$ & $\begin{array}{l}45(72.6) \\
18(29)\end{array}$ & $\begin{array}{l}5(45.5) \\
6(54.5)\end{array}$ & $\begin{array}{l}40(78.4) \\
12(23.5)\end{array}$ & 0.034 \\
\hline $\begin{array}{l}\text { DCIS present with IBC }(\mathrm{n}=45) \\
\text { Yes } \\
\text { No }\end{array}$ & $\begin{array}{l}26(57.8) \\
19(42.2) \\
\end{array}$ & $\begin{array}{l}4(80.0) \\
1(20.0)\end{array}$ & $\begin{array}{l}22(55.0) \\
18(45.0) \\
\end{array}$ & 0.378 \\
\hline $\begin{array}{l}\text { Tumor histological grade } \\
\text { I } \\
\text { II } \\
\text { III }\end{array}$ & $\begin{array}{l}20(32.2) \\
33(53.2) \\
9(14.5) \\
\end{array}$ & $\begin{array}{l}3(27.3) \\
6(54.5) \\
2(18.2)\end{array}$ & $\begin{array}{l}17(33.3) \\
27(52.9) \\
7(13.7) \\
\end{array}$ & 0.905 \\
\hline $\begin{array}{l}\text { HR status** } \\
\text { Positive } \\
\text { Negative }\end{array}$ & $\begin{array}{c}54(87.1) \\
6(9.7) \\
\end{array}$ & $\begin{array}{l}9(81.8) \\
2(18.2)\end{array}$ & $\begin{array}{c}45(88.2) \\
4(7.8) \\
\end{array}$ & 0.302 \\
\hline $\begin{array}{l}\text { HER2 status for IBC }(\mathrm{n}=43)^{* *} \\
\text { Amplified } \\
\text { Nonamplified }\end{array}$ & $\begin{array}{c}3(7.0) \\
40(93.0) \\
\end{array}$ & $\begin{array}{c}0 \\
5(100) \\
\end{array}$ & $\begin{array}{c}3(7.9) \\
35(92.1) \\
\end{array}$ & 1.000 \\
\hline
\end{tabular}

*1 patient with missing imaging to determine clinical tumor size in the no upgrade group

**2 patients with missing prognostic markers, both were in the no upgrade group 
Table 3. ADH characteristics

\begin{tabular}{|l|c|c|c|c|}
\hline & $\begin{array}{c}\text { All patients with } \\
\text { ADH and } \\
\text { ipsilateral } \\
\text { malignancy }\end{array}$ & $\begin{array}{c}\text { Upgrade } \\
\text { group }\end{array}$ & $\begin{array}{c}\text { No upgrade } \\
\text { group }\end{array}$ & p-value \\
\hline $\begin{array}{l}\text { Distance between ADH and cancer, } \\
\text { cm [mean (std)]*** }\end{array}$ & $4.55(2.44)$ & $4.39(2.32)$ & $4.58(2.49)$ & 0.397 \\
\hline ADH target size, cm [mean (std)]*** & $1.77(2.06)$ & $0.99(0.41)$ & $1.91(2.21)$ & 0.962 \\
\hline Biopsy modality of ADH & $21(33.9)$ & $1(9.1)$ & $20(39.2)$ & 0.019 \\
Stereotactic & $21(33.9)$ & $8(72.7)$ & $13(25.5)$ & \\
US & $20(32.3)$ & $2(18.2)$ & $18(35.3)$ & \\
MRI & $44(71)$ & $7(63.6)$ & $37(72.5)$ & \\
\hline Number of ADH foci $* * *$ & $16(25.8)$ & $4(36.4)$ & $12(23.5)$ & \\
$<3$ & $4(6.7)$ & 0.462 & $4(7.8)$ & \\
$\geq 3$ & $56(93.3)$ & $11(100)$ & $45(88.2)$ & \\
\hline ADH micropapillary features*** & & & & \\
Yes & $5(8.3)$ & $3(27.3)$ & $2(3.9)$ & 0.039 \\
No & $55(91.7)$ & $8(72.7)$ & $47(92.2)$ & \\
\hline ADH cell necrosis*** & & & \\
Yes & & & \\
No & & & & \\
\hline
\end{tabular}

***2 patients with imaging and slides not available to review ADH size, foci, micropapillary features, or cell necrosis, both in the no upgrade group 


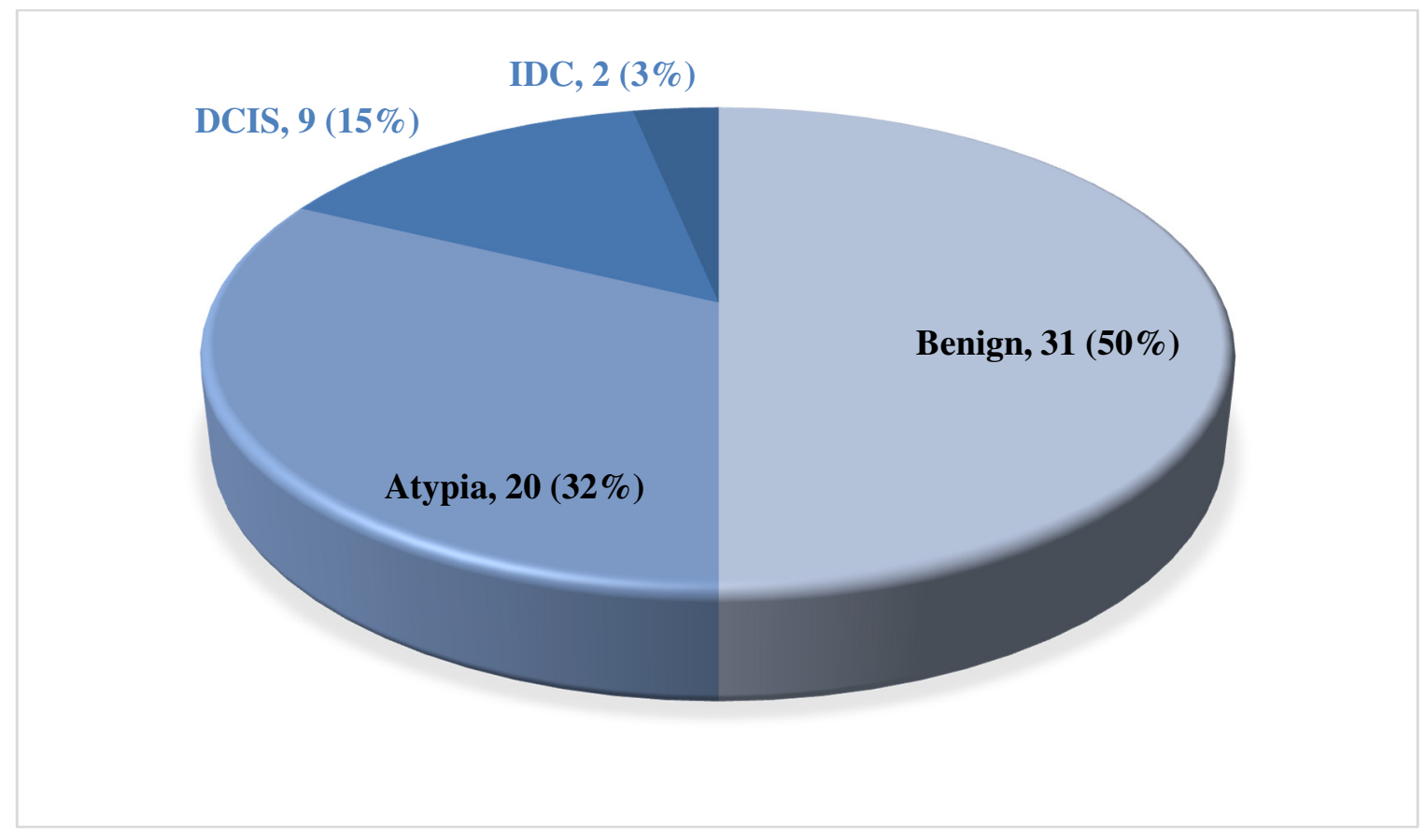

Figure 1. Surgical pathology at site of ADH 
Table 4. Bivariate analysis of variables associated with upgrade

\begin{tabular}{|l|c|c|c|}
\hline Factors & Unadjusted OR & $95 \%$ CLs & p-value \\
\hline Age $<50$ at diagnosis & 1.037 & $0.1908,5.6364$ & 0.9664 \\
\hline Non-Caucasian ethnicity & 3.030 & $0.7766,11.8249$ & 0.1105 \\
\hline Clinical tumor size $>1 \mathrm{~cm}$ & 0.7982 & $0.1796,3.5487$ & 0.7672 \\
\hline DCIS tumor type & 4.3636 & $1.1182,17.0278$ & 0.0339 \\
\hline HR positive cancer & 0.4000 & $0.0634,2.5239$ & 0.3296 \\
\hline $\begin{array}{l}\text { Distance between ADH } \\
\text { and cancer } \leq 3 \mathrm{~cm}\end{array}$ & 2.400 & $0.6049,9.5224$ & 0.2131 \\
\hline $\begin{array}{l}\text { ADH biopsy with US } \\
\text { guidance }\end{array}$ & 12.3077 & $1.3733,110.30$ & 0.0249 \\
\hline ADH size $>1 \mathrm{~cm}$ & 1.3474 & $0.3218,5.6420$ & 0.6832 \\
\hline ADH extent (>2 foci) & 1.7619 & $0.4387,7.0763$ & 0.4246 \\
\hline ADH with necrosis & 8.8128 & $1.2665,61.3166$ & 0.0279 \\
\hline
\end{tabular}

Table 5. Multivariate analysis of variables associated with upgrade

\begin{tabular}{|l|c|c|c|}
\hline Factors & Adjusted OR & $95 \%$ CLs & p-value \\
\hline $\begin{array}{l}\text { ADH biopsy with US } \\
\text { guidance }\end{array}$ & 44.8986 & $2.1709,928.58$ & 0.0138 \\
\hline DCIS tumor type & 11.5209 & $1.1509,115.32$ & 0.0161 \\
\hline ADH with necrosis & 10.6860 & $0.7464,152.99$ & 0.0630 \\
\hline
\end{tabular}




\section{Chapter V: Discussion}

The overall upgrade to underlying malignancy at the site of $\mathrm{ADH}$ was $17.7 \%$ when there was an ipsilateral breast cancer present. As hypothesized, this upgrade rate was not significantly more elevated in this cohort with an ipsilateral malignancy, when compared to the contemporary upgrade rate of $18-39 \%$ in the prior studies without the presence of an ipsilateral malignancy. This also matches our institutional upgrade rate of $17.7 \%$ when our own upgrade rate was examined. ${ }^{16}$ Historically, it has been assumed that the site of ADH was at higher risk for upgrade because of the presence of an ipsilateral cancer, which warranted surgical excision of the site of $\mathrm{ADH}$. To the best of my knowledge, this is the first study to have defined this upgrade rate, particularly with attention to the multidisciplinary features assessed.

We found that though not statistically significant, younger patients were at higher risk of upgrade. This is in contrast to Ko and colleagues who found age $>50$ to be significantly associated with upgrade. ${ }^{32}$ Older age was also found to be associated with upgrade in subsequent studies by Chae, Mcghan, Menes, and Uzan. ${ }^{11,12,15,31}$ Ethnicity was not reported as significant in other studies, and though it did not reach significance in this cohort, being of non-Caucasian ethnicity was associated with a 3-fold risk of upgrade.

When considering the pathologic features associated with the ADH, many studies noted the size of the targeted lesion and the extent of the $\mathrm{ADH}$ (ie. $>2$ foci) to be associated with upgrade..$^{8,10,17,33}$ While the extent of ADH trended toward significance in this cohort with an unadjusted OR of 1.7, the radiographic size of $\mathrm{ADH}$ on preoperative imaging was essentially inversely related to upgrade. We did find the presence of individual cell necrosis in the ADH carried an 8-fold risk of upgrade, which was consistently identified by others to be associated with upgrade as well..$^{6,8,10,13,17}$ Also, having a breast specific pathologist confirming the diagnosis 
of $\mathrm{ADH}$ for each patient included in the cohort significantly decreases the concern about interobserver variability and undercalling a DCIS or IBC as ADH.

When considering the additional radiographic features of $\mathrm{ADH}$, I was not able to quantify how much of the target associated with ADH was excised by the biopsy for this study, which has been found to be significant in multiple studies. ${ }^{13,16,29,33,34}$ As expected, when the target is undersampled, these lesions were more likely to upgrade. A surrogate for undersampling could be biopsy modality used to sample the target. In our practice, stereotactic and MR-guided biopsies routinely use vacuum-assistance, larger-bore needles, and remove $>6$ cores. Biopsy with sonographic-guidance does not routinely utilize vacuum-assistance and frequently $<6$ cores are removed with 12-14-gauge needle, resulting in less of the target being evaluated before surgical excision. The indication for the biopsy at the site of ADH were not recorded. Frequently in practice, calcifications would be sampled using stereotactic biopsy, mass or non-mass enhancement with no ultrasound correlate would be sampled using MR-guidance, and masses would be sampled using sonographic guidance. To a breast radiologist, a mass seen on ultrasound would have the most concern for underlying malignancy of these three presentations. Therefore, it is not surprising that patients who had ADH diagnosed by ultrasound biopsy were at 12-fold risk of upgrade.

Unique to our study is the presence of an ipsilateral malignancy. Focusing on the features of the malignancy, ADH was more likely to upgrade when DCIS was present, either alone, or in association with an IBC. Although I know of no studies that suggests DCIS is more likely to be multifocal or multicentric compared to IBC, DCIS can present with skip lesions, whereas IBC is more likely to be a discrete entity. To meet inclusion criteria for this study, the ADH and site of malignancy were required to be separate distinct lesions $\geq 1 \mathrm{~cm}$ apart, which should be far 
enough apart to not include DCIS skip lesions which are really all one entity. Interestingly, all other malignancy features were non-significant, including tumor size, grade, hormone receptor or HER2 status. In addition, even when the ADH was in closer proximity to the ipsilateral cancer, there does not appear to be a higher risk of upgrade, than if the ADH was identified without an ipsilateral breast cancer.

Therefore, based on these findings, it is reasonable to consider omission of surgical excision in a select group of patients with percutaneous biopsy diagnosis of ADH with a concurrent ipsilateral breast cancer, similar to the stratification models being developed for solitary ADH. We need to continue to develop the criteria for both presentation types to identify the patients at a low risk for upgrade. This data significantly contributes to the assessment, approach, and appropriate identification of patients that can safely undergo active surveillance and avoid surgical excision. Unlike those with a solitary site of ADH, patients with an ipsilateral breast cancer and $\mathrm{ADH}$ who undergo lumpectomy for management of their cancer will frequently have additional adjuvant therapy, including whole breast radiation and endocrine therapy for at least 5 years. Each of these adjuvant therapies will provide additional protection to the breast to decrease the risk of recurrence or future breast cancers.

When focusing on the group that is typically offered observation over excision at our institution (ADH target $<1 \mathrm{~cm}$, no $\mathrm{ADH}$ necrosis, $<3$ foci of $\mathrm{ADH}$ ), this would result in an upgrade rate of $8 \%$ in this cohort (2/25 patients). If we excluded those who underwent US guided biopsy, as this biopsy modality was significantly associated with upgrade, the resulting upgrade rate is $0 \%$. Though this was a limited number of patients in this study (16/62 patients, $26 \%)$, it appears that this would be a safe group to elect for observation of the site of ADH, with a very low risk of missing an underlying malignancy in the ipsilateral breast. Caution should also be 
taken when the ipsilateral malignancy is DCIS, as this was also significantly associated with upgrade. When excluding patients with ipsilateral DCIS from this group, the upgrade rate continues to be $0 \%$.

We have learned from Menen's study that not excising a site of ADH can be oncologically appropriate. In their study, 125 women underwent active surveillance after percutaneous biopsy diagnosed $\mathrm{ADH}$. Compared to a group that underwent surgical excision, the likelihood of developing a cancer either at the site of biopsy or in the ipsilateral breast were not different ( $\mathrm{p}=0.49$ and 1.00 ) between the groups. Only $24 \%$ of women in this study received chemoprevention. ${ }^{35}$ Therefore, it seems likely that for women meeting strict multidisciplinary criteria, who have a low risk of upgrade could avoid excision of the site of ADH, particularly when they will receive additional adjuvant therapy as treatment for the ipsilateral malignancy.

\section{Limitations}

This is a retrospective review from a single institution with a relatively small sample size. Also, breast imaging reports do not consistently note the percent of the target excised, or the percent of the target remaining after percutaneous biopsy, so this parameter was not able to be included in the analysis. However, size of the target and biopsy modality can be correlates for how well the target would be sampled. With ultrasound-guided biopsy, this is the least likely to have vacuum-assistance, which results in less tissue to removed and more potential for undersampling, and therefore more likely to upgrade.

\section{Considerations for Future Research}


For future research, further investigation can be made into the radiographic characteristics such as percent of the target sampled in this patient cohort. In addition, the application of MR enhancement at the site of the ADH may also be a useful tool to decide about need for excision. Application of these findings to clinical practice can then begin. All patients will be prospectively identified and delegated into groups appropriate for observation or recommend excision. All patients are then screened appropriately after their cancer treatment for recurrence or new malignancy. As we start to accumulate patients in the group who do not have the site of ADH excised, we will be able to compare outcomes of ipsilateral breast cancer recurrence or future malignancy to those who underwent excision of the site of ADH to determine the safety of observation in this patient population. 


\section{References}

1. https://www.cancer.org/content/dam/cancer-org/research/cancer-facts-andstatistics/breast-cancer-facts-and-figures/breast-cancer-facts-and-figures-2017-2018.pdf:

2. $\quad$ Fisher B, Anderson S, Bryant J, et al: Twenty-Year Follow-up of a Randomized Trial Comparing Total Mastectomy, Lumpectomy, and Lumpectomy plus Irradiation for the Treatment of Invasive Breast Cancer. New England Journal of Medicine 347:1233-1241, 2002

3. Fisher B, Redmond C, Poisson R, et al: Eight-Year Results of a Randomized Clinical Trial Comparing Total Mastectomy and Lumpectomy with or without Irradiation in the Treatment of Breast Cancer. New England Journal of Medicine 320:822-828, 1989

4. Meyer JE, Christian RL, Lester SC, et al: Evaluation of nonpalpable solid breast masses with stereotaxic large-needle core biopsy using a dedicated unit. American Journal of Roentgenology 167:179-182, 1996

5. Hartmann LC, Degnim AC, Santen RJ, et al: Atypical Hyperplasia of the Breast — Risk Assessment and Management Options. New England Journal of Medicine 372:78-89, 2015

6. Ely KA, Carter BA, Jensen RA, et al: Core Biopsy of the Breast With Atypical Ductal Hyperplasia: A Probabilistic Approach to Reporting. The American Journal of Surgical Pathology 25:1017-1021, 2001

7. Krishnamurthy S, Bevers T, Kuerer H, et al: Multidisciplinary Considerations in the Management of High-Risk Breast Lesions. American Journal of Roentgenology 198:W132W140, 2012

8. Wagoner MJ, Laronga C, Acs G: Extent and Histologic Pattern of Atypical Ductal Hyperplasia Present on Core Needle Biopsy Specimens of the Breast Can Predict Ductal Carcinoma In Situ in Subsequent Excision. American Journal of Clinical Pathology 131:112121,2009

9. B Bevers T, Anderson B, Bonaccio E, et al: NCCN clinical practice guidelines in oncology: breast cancer screening and diagnosis, 2009

10. Allison KH, Eby PR, Kohr J, et al: Atypical ductal hyperplasia on vacuumassisted breast biopsy: suspicion for ductal carcinoma in situ can stratify patients at high risk for upgrade. Human Pathology 42:41-50, 2011

11. McGhan LJ, Pockaj BA, Wasif N, et al: Atypical Ductal Hyperplasia on Core Biopsy: An Automatic Trigger for Excisional Biopsy? Annals of Surgical Oncology 19:32643269,2012

12. Menes TS, Rosenberg R, Balch S, et al: Upgrade of high-risk breast lesions detected on mammography in the Breast Cancer Surveillance Consortium. The American Journal of Surgery 207:24-31, 2014

13. Nguyen CV, Albarracin CT, Whitman GJ, et al: Atypical Ductal Hyperplasia in Directional Vacuum-Assisted Biopsy of Breast Microcalcifications: Considerations for Surgical Excision. Annals of Surgical Oncology 18:752-761, 2011

14. Sneige N, Lim SC, Whitman GJ, et al: Atypical Ductal Hyperplasia Diagnosis by Directional Vacuum-Assisted Stereotactic Biopsy of Breast MicrocalcificationsConsiderations for Surgical Excision. American Journal of Clinical Pathology 119:248-253, 2003

15. Uzan C, Mazouni C, Ferchiou M, et al: A Model to Predict the Risk of Upgrade to Malignancy at Surgery in Atypical Breast Lesions Discovered on Percutaneous Biopsy Specimens. Annals of Surgical Oncology 20:2850-2857, 2013 
16. Williams KE: Radiologic and Pathologic Features Associated With Upgrade of Atypical Ductal Hyperplasia at Surgical Excision. Academic Radiology, 2018

17. Forgeard C, Benchaib M, Guerin N, et al: Is surgical biopsy mandatory in case of atypical ductal hyperplasia on 11-gauge core needle biopsy? a retrospective study of 300 patients. The American Journal of Surgery 196:339-345, 2008

18. Amin A: Atypical ductal hyperplasia on percutaneous biopsy--Stratification to determine need for excision, The University of Kansas Health System, 2017

19. Simpson PT, Reis-Filho JS, Gale T, et al: Molecular evolution of breast cancer. The Journal of Pathology 205:248-254, 2005

20. Burstein HJ, Polyak K, Wong JS, et al: Ductal Carcinoma in Situ of the Breast. New England Journal of Medicine 350:1430-1441, 2004

21. Rosen P: The pathological classification of human mammary carcinoma: past, present and future. Annals of clinical and laboratory science 9:144-156, 1979

22. Azzopardi JG: Problems in breast pathology. Philadelphia, Saunders, 1979 pp. 244

23. Ellis IO SS, Sartre-Garau X: WHO Classification of Tumours: Pathology and Genetics of Tumours of the Breast and Female Genital Organs. Lyon, IARCPress, 2003 pp. 1359

24. Racz JM: When Does Atypical Ductal Hyperplasia Require Surgical Excision? Surg Oncol Clin N Am 27:23-32, 2018

25. Page D: Atypical hyperplastic lesions of the female breast. A long-term follow-up study. Cancer 55:2698-2708, 1985

26. Elmore JG, Longton GM, Carney PA, et al: Diagnostic concordance among pathologists interpreting breast biopsy specimens. JAMA 313:1122-1132, 2015

27. Kohr JR, Eby PR, Allison KH, et al: Risk of Upgrade of Atypical Ductal Hyperplasia after Stereotactic Breast Biopsy: Effects of Number of Foci and Complete Removal of Calcifications. Radiology 255:723-730, 2010

28. Khoury T, Chen X, Wang D, et al: Nomogram to predict the likelihood of upgrade of atypical ductal hyperplasia diagnosed on a core needle biopsy in mammographically detected lesions. Histopathology 67:106-120, 2015

29. Linsk A, Mehta TS, Dialani V, et al: Surgical upgrade rate of breast atypia to malignancy: An academic center's experience and validation of a predictive model. The Breast Journal 24:115-119, 2018

30. Co M, Kwong A, Shek T: Factors affecting the under-diagnosis of atypical ductal hyperplasia diagnosed by core needle biopsies - A 10-year retrospective study and review of the literature. International Journal of Surgery 49:27-31, 2018

31. Chae B: Predictive factors for breast cancer in patients diagnosed atypical ductal hyperplasia at core needle biopsy. World Journal of Surgical Oncology 7, 2009

32. Ko E, Han W, Lee JW, et al: Scoring system for predicting malignancy in patients diagnosed with atypical ductal hyperplasia at ultrasound-guided core needle biopsy. Breast Cancer Res Treat 112, 2008

33. Latronico A, Nicosia L, Faggian A, et al: Atypical ductal hyperplasia: Our experience in the management and long term clinical follow-up in 71 patients. The Breast 37:1-5, 2018 
34. Peña A, Shah SS, Fazzio RT, et al: Multivariate model to identify women at low risk of cancer upgrade after a core needle biopsy diagnosis of atypical ductal hyperplasia. Breast Cancer Research and Treatment 164:295-304, 2017

35. Menen RS, Ganesan N, Bevers T, et al: Long-Term Safety of Observation in Selected Women Following Core Biopsy Diagnosis of Atypical Ductal Hyperplasia. Annals of Surgical Oncology 24:70-76, 2017 